\section{Thin film devices}

Active and Passive Thin Film Devices. Edited by T. J. Coutts. Pp. 858. (Academic: New York, London and San Francisco, 1978.) $£ 60$.

IF one expects the value of a technical work to keep pace with its cost and size then at a price of $£ 60$ at a weight of over $3 \mathrm{lb}$ a purchaser is likely to be disappointed with the work under review. Unfortunately the subject matter is neither sufficiently thorough in its range nor adequately coordinated to constitute a satisfactory reference text on the chosen theme. How, you may ask, is this possible with 858 pages at the editor's disposal: the answer is that the editor has not adopted a policy towards his reader when choosing the subject matter. This is an applied physicist's work not an engineer's, and equal emphasis is given to realised devices as well as promising ones and failures, which might be acceptable if the reader were warned accordingly at the outset.

The book, containing thirteen chapters by specialists, covers thin film preparation, electrical properties of film materials and their uses or potential uses as passive elements and active components. The chapters describing solar cells, optical waveguides and magnetic and superconducting devices are useful reviews, but the references and appended notes indicate that the book was written by 1976 . Nearly two years in printing is too long for such a rapidly moving field; consequently molecular beam epitaxy is given a proof reference and solar thermal converters which are in advanced development receive three lines of tcxt.

The development history of thin film systems is littered with failures in deposition techniques and film materials, but such is the speed with which novel devices are invented that the search for new materials and growth processes continues unabated (except perhaps in the UK). Under such circumstances what should an editor include in a book on thin film devices? First, he must decide to whom the collected reviews are directed: the dust-cover suggests physicists, electronic and production engineers and material scientists. This is a broad readership that one cannot expect to have the discrimination of specialists when judging which devices are of practical value and which of historical interest. Thus the editor has given the same emphasis to thin film transistors and threshold switches (although their effective use after a decade is still awaited) as to resistors, capacitors, photoconductors, and so on. Of course one does not want to waste knowledge of physical character- istics arising from an unfulfilled product development but much of this could have been discussed in the chapters devoted to electrical properties of film materials. In view of the importance of silicon technology the most serious weakness perhaps is the omission of a chapter solely devoted to the growth and uses of epitaxial and amorphous silicon and of silicon compound films. Also there is an artificiality in restricting discussion to wholely thin film systems when thin films are so vital a part of most solid-state devices.

When discussing the history of the use of thin films in electronics $T$. J. Coutts states that there would have been no advantage of using thin film resistors in the period of bulky valve circuitry, but the requirements of microminiaturisation made their use essential. This is an incomplete view of what occurred. Thin film resistors using $\mathrm{NiCr}$ alloys came into use in World War II for waveguide attenuators and were later used for precision resistors. The reason why vacuum deposited films were not used in valve circuits was that they broke down when operated at voltages in the $100 \mathrm{~V}$ region. However, development continued in the 1950s on transparent conducting coatings for windows and on the deposition of insulating films and the metallising of capacitor foils (which commenced before the War). Thus, considerable know-how existed

\section{Reflection seismology}

Reflection Seismology: A Tool for Energy Resource Exploration. By K. H. Waters. Pp. 377. (Wiley: New York and Chichester, UK, 1978.) $£ 19.75$.

By far the most successful method of determining the structure of the upper few kilometres of the Earths' crust has been and continues to be the art and science of reflection seismology. This book provides an essentially complete survey of the subject from the basic physical principles to the multitude of data generation and analysis tools currently used by the oil exploration industry. The volume is perhaps too short on mathematics. However, the physics, including the underlying assumptions of each technique, are generally well presented.

The volume begins with a general description of the pertinent aspects of elastic wave propagation in the upper crust of the Earth. Following chapters cover seismic energy generation techniques, data-gathering methods, stack- on passive devices when the transistor became a production item and a more correct view is the convergence of technologies resulting in the manufacture of hybrid and integrated circuits.

In the chapter on "Preparation Methods for Thin Film Devices" the author has chosen to describe a variety of techniques rather than concentrate on specific kinds favoured for making the devices considered in the other chapters. The emphasis given to metal filaments and boats for evaporation suggests a subject treatment one would have found a decade or more ago and the availability of such refractory materials as $\mathrm{B} / \mathrm{Ti} / \mathrm{N}$ complexes for the high rate evaporation of aluminium is not mentioned. Also magnetron sputtering is not described although it has helped to cause a renaissance in the use of sputtering in solid-state technology and most of the advances leading to cylindrical and planar magnetrons were made by 1974 , that is, before the book was written.

The book is not an embracing text, and is inadequate in its treatment of deposition processes and lacks balance in its choice of devices. However, as stated above, there are several specialist chapters which are valuable reviews.

L. Holland is Head of the Unit for Plasma Materials Processing at the University of Sussex, UK.

ing and filtering techniques, and the reduction of processed data to the geometry and physical properties of the rock formations below. Introductions to such recent and current topics as homomorphic deconvolution, adaptive filtering, maximum entropy spectral analysis, integral and differential wave equation migration, shear waves, high frequency methods and threedimensional data collection and analysis are included.

The professional exploration seismologist will find that they know a great deal more about many of the subjects covered in this book, and students whose desire is a thorough knowledge of any given topic will require a more detailed and explanatory presentation. However, the volume is well referenced (up to about 1973). The book is appropriate and recommended for those who want a basic technical introduction to exploration seismology from beginning to end.

Tom Landers

Tom Landers is a staff member at the Applied Seismology Group of Lincoln Laboratory, Massachusetts Institute of Technology, Cambridge, Massachusetts. 